\section{CITES: what role for science?}

From 10 to 20 April 2000, the UNEP headquarters in Nairobi was host to the 11th Meeting of the Conference of the Parties (CoP) to CITES. As is usual at these meetings, one or two issues dominated the proceedings both inside the meeting and on the fringes. In many ways, the meeting was something of an anti-climax with the expected fierce debates about elephants and whales in particular failing to materialize. Other issues followed a predictable course and there were no ground-breaking decisions to celebrate. From a first timer's point of view, four elements stand out as being major influences on decision-making, both at present and in the future.

- The narrow focus on charismatic megavertebrates such as elephants dominates the CITES debate in a way that can obscure other equally important issues.

- Science is a valuable tool in the CITES debate, but it cannot necessarily provide a definitive answer. It is interesting to note how the same science can be used to support the arguments of those who hold essentially diametrically opposed viewpoints.

- Significant for the future role of CITES is how it relates to other Conventions and international agencies and bodies with regard to its decision-making. This is most evident in the debates about whales and elephants.

- CITES will only succeed in the long term when there is a change in attitudes to wildlife trade, particularly in those countries where demand is fuelling illegal trade.

Coming from a scientific background - and working for an organization that attempts to base all its decisions on sound science-I feel decisions at CITES must, where possible, be based on good science rather than emotion. There are, however, difficulties in this approach as I discuss later. There was a relatively small number of organizations at the CITES conference, Flora \& Fauna International (FFI), Trades Records Analysis of Flora and Fauna (TRAFFIC), IUCN and WWF among them, that appeared to follow this road.

Predictably, the African elephant was an overwhelming presence at CITES. The debate continues between those who feel the species is highly threatened and that trade in its valuable tusks should be banned, and those who feel this trade is the only way to ensure the species' future in the long term. As at the last CoP in Harare, the debate polarized between the central African countries, led by Kenya, who, with India, argued that the one-off sale of ivory agreed in Harare had encouraged an increase in poaching and that all elephant populations should be listed on Appendix 1. On the other hand, representatives of southern African nations argued that their elephant populations are healthy and increasing, and that trade in ivory will provide much-needed funds for conservation. The final decision was both a triumph and a disappointment. A triumph in the sense that the African countries themselves agreed a compromise that effectively bans any ivory trade until the next CoP, a disappointment in that it still does not resolve the key issue, namely the vastly differing views of central and southern African countries. The debate will now resurface at the 12 th CoP, in 2 years' time, although at least by that stage the results from the Monitoring of the Illegal Killing of Elephants (MIKE) scheme will be available. For some populations there is good scientific evidence that they are healthy and increasing (in some cases causing a worrying rise in elephant-human conflicts), and from a personal point of view it seems reasonable to support a limited amount of well-controlled trade in ivory.

The limitations of science and the relationship to other Conventions and organizations were evident in the debates over marine species. Compared with counting elephants, estimating population sizes for species such as hawksbill turtles, basking sharks and minke whales is an inexact science. In addition, the track record of fisheries management regimes has not been a happy one. The size of the hawksbill turtle population and the validity of its listing as Critically Endangered was a major source of argument in the debate over whether to allow Cuba to sell its stockpiled turtle shells accumulated from a controlled annual harvest. The criteria for listing species in the IUCN Red List Categories are not perfect (which is why they are currently being refined). Moreover, for marine species they may never provide an exact answer; for such species it may be churlish to expect this will ever happen, but we do have the precautionary principle that promotes the idea that if in doubt, think the worst. Many organizations agreed there was a need for a regional consensus, particularly as all concurred that a large proportion of the Cuban 'population' was shared with other countries. The need for a regional workshop on turtles was accepted although one anticipates a long and bitter argument before any agreement can be reached.

CITES does not operate in a vacuum-its decisions may have far-reaching ramifications in other fora. This is especially true in the debates over whales and sharks. The relationship between CITES and the International Whaling Commission (IWC) has been close in terms of decision-making. Both bodies have agreed to link their decisions so that one is not out of step with the other. 
For CITES, primary responsibility for the conservation of whale species rests with the IWC. The CoP again resisted (although in one case by a very small margin) the proposals to downlist any whale populations that would have allowed the resumption of commercial whaling. Again science was used to show that populations could sustain a commercial harvest. However, the possible impacts on other much more threatened populations were not clear-treating stocks of marine species as easily definable entities is again an inexact science. From a scientific point, there appears to be an argument that some stocks could be harvested commercially, although the final decision should rest with the IWC.

For sharks, the argument was neatly reversed. In this case, those arguing against listing sharks on the Appendices felt it should be the UN's Food and Agriculture Organization (FAO) that should be the sole organization responsible for their conservation. For some, this would be like leaving the fox in charge of the chicken run. FAO is a fisheries management organization and, as mentioned earlier, fisheries management is not a field that has many conservation successes to boast about. Even the FAO themselves appeared to agree that the conservation of sharks might be best left to CITES. The fact that this statement appeared in a draft FAO document finally sank the argument for listing. However, for basking sharks, the vote was very close. This debate will continue, and the prospects look good if the FAO grasp the conservation nettle. Interestingly, science was again used in the debate over sharks, though in this case the lack of evidence of decline was used as an argument against listing. If there is evidence of widespread declines or collapses in fisheries, does this really mean the species is threatened? The words 'precautionary principle' come to mind. In this case, do we wait until all the information is available to tell us that a species is definitely extinct or do we act now on what information we have? For sharks, declines in fisheries and the increasing demand for their highly valuable fins, which are, amongst other things, used to make soup, are surely enough to cause grave concern.

Some argue that CITES has singularly failed to prevent the continued decline in populations of the tiger and if one cannot save such a high profile and charismatic species, what hope is there for the many others in need of help? This argument was reinforced when listening to the report of the high-level tiger missions that had visited both range states and countries that consume tiger products. Despite the huge amounts of effort and money expended, tigers are still in decline. India was heavilv criticized to the extent that it was even suggested by some that trade sanctions be imposed. The crux of the problem is continued demand for tiger parts and inadequate enforcement. In this case, science is not the answer. Instead, there is a need for attitudes to change.

The question of attitudes also arises when tackling the issue of shahtoosh. Tibetan antelopes or chiru are poached for their wool which is used to make shawls so fine they can be threaded through a wedding ring. They are the ultimate fashion accessory and can cost up to $\$ 10,000$ each. CITES has a role to play in controlling this trade, but ultimately it is the attitudes of those who demand such products that need to change.

The continuing theme of attitudes brings me neatly to the issue of plant conservation. As a first timer, one could be forgiven for thinking that CITES only deals with big, charismatic animals. Plants feature a long way down the agenda. Unlike the lengthy debates on elephants and whales, most of the debate on proposals to amend the listing for plant species was over in a day. Clearly, plants cannot command the emotional appeal of elephants, but unless the issue of trade in plant species, particularly timber, is properly addressed, the habitat will not be available for the charismatic species to use. It is all a question of attitude.

For CITES to be truly effective, it must evolve. The obsession with one or two high profile species such as elephants distracts attention from many other pressing problems for less charismatic species of plants and animals. Science is an important tool and should be used wherever possible. But it does not provide all the answers and we should not be obsessed with finding the right figures whilst the species in question becomes extinct. Finally, CITES can only do so much. In the case of tigers, it has failed to prevent the decline because the attitudes of those whose consume tiger products has not changed. Until attitudes to wildlife trade in general change amongst those who hold the key to a species survival, CITES will be partially successful only.

\footnotetext{
Simon Mickleburgh

Senior Conservation Researcher

Fauna \& Flora International

Great Eastern House, Tenison Road

Cambridge CBI 2TT UK
} 